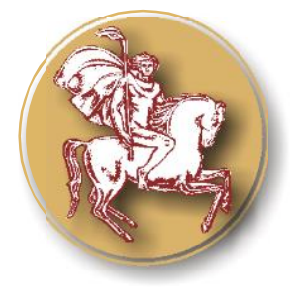

Trakia Journal of Sciences, No 4, pp 336-344, 2021

Copyright (C) 2021 Trakia University

Available online at:

http://www.uni-sz.bg

ISSN 1313-3551 (online)

doi:10.15547/tjs.2021.04.007

Original Contribution

\title{
BUILDING DYNAMIC CAPABILITIES - A FACTOR FOR SUSTAINABLE DEVELOPMENT OF THE FIRM
}

\author{
A. Marichova* \\ Social Sciences Department, University of Architecture, Civil Engineering and Geodesy, Sofia, Bulgaria
}

\begin{abstract}
Purpose: In recent years, every firm is facing serious challenges related to the implementation of the principles of sustainable development, which requires a significant change in strategic behavior, strategic decisions and company actions. The aim of the study is to develop a practicable model of dynamic capabilities supporting the sustainable development of the firm, which includes recognizable, understandable and measurable components for managers, and ensures the realization of competitive advantages in the three dimensions (economic, environmental and social) and performance, taking into account the dynamics of the environment.

Method: The study uses a method based on data collection through an online survey and statistical analysis of dependencies in the model, using a correlation coefficient.

Results: The results of an empirical study conducted in 123 firms operating in different markets will prove the interrelationships and dependencies in the developed model of dynamic capabilities, supporting sustainability and their impact on the process of building competitive advantages.

Conclusions: The research and the conclusions made prove the necessity from building dynamic capabilities, supporting the sustainable development of the firm, as a factor that ensures the realization of competitive advantages in the three dimensions (economic, environmental and social) and performance, taking into account the dynamics of the environment.
\end{abstract}

Key words:Dynamic Capabilities, Sustainable Practices, Competitive Advantages (Economic, Environmental, Social), Functional Competencies, Performance

\section{INTRODUCTION}

In today's dynamic conditions, synchrony, coordination of actions and search for a balance between the interests of business, people (consumers), and society is increasingly needed. In practice, this means achieving economic, environmental, and social goals through sustainable development that meets the needs of the present, without compromising the ability of future generations to meet their own needs (1).

\footnotetext{
*Correspondence to: Aneta Marichova, Social Sciences Department, University of Architecture, Civil Engineering and Ge odesy, 1 Hristo Smirnensky, 1046-Sofia, Bulgaria E-mail: aneta.marichova@abv.bg
}

These challenges require a complete change in the company's vision and the inclusion of new sustainable practices in the overall set of business practices. The ultimate goal is to implement a strategy that allows the creation, offering and implementation of additional economic, social and environmental value for the client, stakeholders and society as a whole, building competitive advantages and performance. There is no single set of sustainable development practices, as each firm has a unique business strategy, but there is a sufficient set of good practices that are applied taking into account its specifics and the market in which it operates (2). Good sustainable practices include first and foremost a set of principles that guide company 
development towards deepening relationships with stakeholders (customers, suppliers, owners, employees, non-governmental organizations, regulators) and achieving a higher level of approval, cooperation and satisfaction on their part. On the other hand, they are a factor for creating distinctive company competencies and a valuable, rarity strategic resource, which provides building competitive advantages in the three dimensions (economic, environmental and social), which in turn is measured by a sufficiently wide range of results, and not just with the realized profit. In other words, sustainable practices are built on the development of internal factors/resources (technology, innovation, motivation, workforce incentives, history, reputation, financial resources and organizational structure, or the creation of distinctive competencies), and external factors (cooperation with stakeholders, integrated vertical chain, government requirements, regulations, etc.), as well as their skillful combination. In practice, this means building a system of dynamic capabilities that are common, fundamental to all companies, but combined with a specific organization (3), which determines the different interests and different success of companies that focus on sustainable development - from imitation of activity, timid attempts to change strategy and behavior, to active change combined with investment, innovation to ensure leadership, authority and trust.

The new challenges facing the firm require the development and expansion of the concept for building dynamic capabilities, which determines the objectives of the proposed study: 1) Development of a practically applicable model of dynamic capabilities supporting the sustainable development of the firm, which includes recognizable, understandable and measurable components for managers, and ensures the realization of competitive advantages in the three dimensions (economic, environmental and social) and performance, taking into account the dynamics of the environment, 2) Empirical study the model of dynamic capabilities, supporting sustainability in firms operating in different markets, to prove the interrelationships and dependencies in the model and the impact on the process of building competitive advantages.

\section{CONCEPTUAL FRAMEWORK}

MARICHOVA A.

Researchers are unanimous that building dynamic capabilities is related to strategic management, strategic behavior and strategic decisions of the firm, which determine the directions of its development in order to build competitive advantage and performance (expressed in financial indicators) by creating, development, and change of company resources in response to changes in the external (micro- and macro) environment.

Initially, dynamic capabilities were defined as a system of the company's ability to integrate, build, develop and change its external and internal resources and competencies to changes in the business environment (4), which ensure its development, growth and building competitive advantages. In the new conditions they are a function not only of the physical, material resources, and above all from the development of intangible resources based on the exchange of ideas, knowledge and communication. Building dynamic capabilities connects external and internal resources with the organization and management in the firm.

Eisenhart and Martin define them as a specific company process, which integrates, reconfigures, acquires and releases resources, as well as organizational, strategic procedures through which the company creates new resources and configurations in order to realize competitive advantages and higher profits in the conditions of constant market dynamics (5). Zolo and Winter define dynamic capabilities as a system for training and creating stable internal and external relationships through which the firm generates higher operational efficiency, which allows it to achieve its long-term goals (6).

Later, other authors define dynamic capabilities as the ability of any firm to identify the need for change, evaluate alternatives, and make appropriate decisions to adapt to external change, which includes strategic and organizational internal change (creates, develops, expands and modifies its resources) (7), but also as a process of company behavior in order to adapt, assimilate the new, reconfigure and change resources and distinctive competencies, in response to external dynamics (8). 
The brief review shows that some of the authors consider the dynamic capabilities of the firm as a factor for the development of external and internal resources in response to changes in the environment, and others - as operational capabilities to renew, development its daily activities to realize advantages. This suggests that it is appropriate to consider the dynamic capabilities hierarchically, at different levels, which composed of functional competencies (market, technological, innovation resources/factors) that allow the company to work in a particular competitive environment, and dynamic capabilities (integration, training, coordination and reconfiguration process), which do not participate directly in the production, but ensure the realization of company goals only through the intermediary role of functional competencies (9).

Today, however, the problem of sustainability and sustainable development of the firm imposes the need to simultaneously solve economic, environmental and social goals and realize competitive advantages. Therefore, the main question is: How can the dynamic capability system support this process in the company and facilitate the building of competitive advantages, what components should be included, how should they be evaluated?

The author defines the dynamic capabilities, supporting the sustainable development of the firm as a complex, multidimensional construction of interconnected and complementary specific activities, which include its ability to identify and analyze the need for economic, environmental and social changes, to develop its own system of solutions for reconfiguration of functional competencies, in response to changes in the external and internal environment, and to implement the necessary actions in order to adapt to them.

Reconfiguration and development of new functional competencies in response to the dynamics in the environment is the ultimate goal of dynamic capabilities. This is a constant process of assimilation, dissemination and integration of new knowledge and technologies based on experience and routine, which allow to implement the process of strategic renewal, taking into account the specifics of the firm. In
MARICHOVA A.

addition, managers must create a new organization and management, integration and coordination of people, tangible and intangible resources to implement the new decisions. In practice, this means developing a new vision and development strategy that takes into account the interests of customers, the company and society.

A source of information that facilitates the firm in making these important decisions is the dynamics of the external environment. The main problem is the development of an effective system for monitoring, assessment of opportunities and threats to development, forecast of expected changes in the external environment, learning (analysis and assimilation of information) and active communication with direct and indirect stakeholders (customers, shareholders, equipment suppliers, raw materials, employees, governmental, non-governmental institutions, media, banks, eco-associations, research institutes and universities).

The indicated components of the dynamic capabilities - monitoring, evaluation of alternatives, learning, stakeholder relations can be defined as dynamic capabilities of a higher, second level (or second order). They are directly related to the dynamics of the external environment and are a function of the senior management team.

The other components - integration, coordination, reconfiguration and creation of a new vision and strategy can be defined as dynamic capabilities of a lower, first level (or first order). They are related to the internal organization and are developed by expanding and improving the managerial skills.

Functional competencies (market, technological, innovative, organizational and managerial competencies, business model) are defined as zero-order capabilities that ensure the operational efficiency. An essential component with strong potential for creating new competitive advantages is the creation of a business model that stimulates the creation of a new product on the principle of the circular economy (10).

Dynamic capabilities affect the firm's ability to change, develop its economic, environmental and social functional competencies in response to the 
growing demands of stakeholders (11). They have an indirect connection (through functional competencies) with the process of building competitive advantages - creating and realizing higher economic, social and environmental value for their clients with a strategy that is not applied by current competitors. Each component of dynamic capabilities is different, unique and offers a specific way to reconfigure functional competencies and create new ones in a way that to provide a competitive advantage for the firm.

On this theoretical basis, the author develops a conceptual model "Building dynamic capabilities supporting the sustainable development of the firm - Competitive advantages (economic, environmental and social) - Performance" (Figure 1) and defines the following hypotheses that must be tested empirically:

Hypothesis 1: The building of dynamic capabilities of second level, supporting the sustainable development of the firm has a
MARICHOVA A.

positive relationship with the realization of competitive advantages (economic, environmental and social) and performance.

Hypothesis 2: The building of dynamic capabilities of first level, supporting the sustainable development of the firm has a positive relationship with the realization of competitive advantages (economic, environmental and social) and performance.

Hypothesis 3: The building of dynamic capabilities, supporting the sustainable development of the firm have a positive relationship with the development and change of functional competencies and the realization of competitive advantages (economic, environmental and social) and performance.

Hypothesis 4: The realized competitive advantages (economic, ecological and social) and performance are a function of the building of the dynamic capabilities and the change of the functional competencies of the firm.

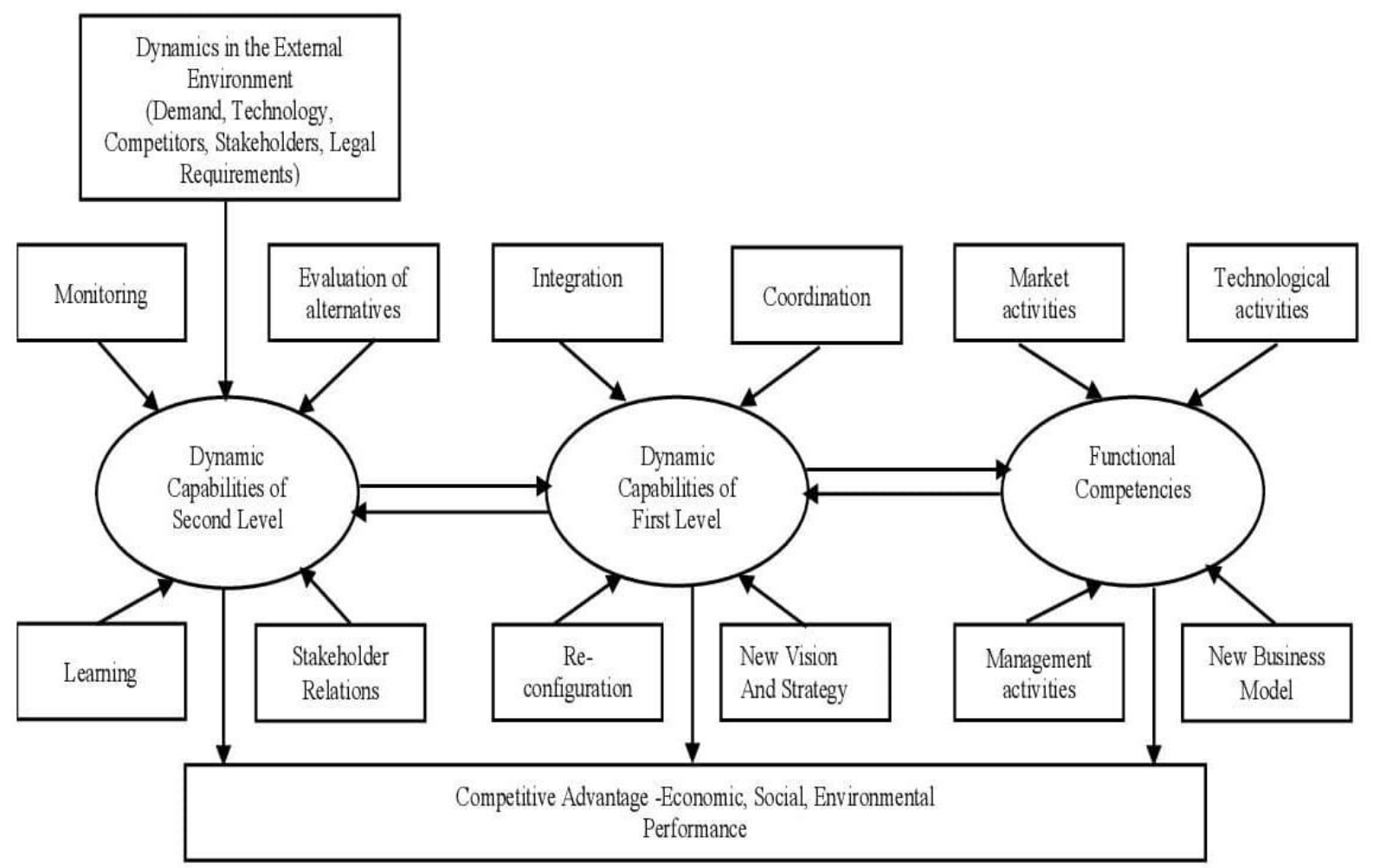

Figure 1. Conceptual model "Building dynamic capabilities, supporting the sustainable development of the firm Competitive advantages (economic, environmental and social) - Performance" 


\section{RESEARCH METHOD}

The empirical research was conducted using a developed and applied methodology for evaluating the defined hypotheses. The survey includes 123 randomly selected firms that have been operating for more than 5 years and have sufficient experience in a dynamic environment. Of these, in the non-financial business sector (industry, construction, transport, logistics, etc.) are $82 \%$, and $18 \%$ - in the financial sector. An equal number of small, medium and large firms operating in different markets and having different specialization, history, territorial location, resources and competencies, business model, and opportunities for sustainable development were studied, which allows to make summaries and conclusions with the necessary objectivity.

The information was collected through an online survey among senior managers of selected firms. Due to the specifics of the researched problem, the survey includes one respondent from each company, who, however, is assumed to have complete information and knowledge about the company he manages. Due to the expressed desire of most of them for confidentiality and anonymity (citing company secret), they were given the opportunity to submit the survey without stating their name or the name of company. Of the questionnaires sent to 320 firms, 218 were returned, 69 of them were rejected due to lack of complete answers and 26 because they worked for less than 5 years, which ultimately led to a sample of 123 firms and 123 managers.

The questionnaire included a total of 32 questions constructed as wordings to which the respondents referred, noting their answers from 1 to 5 on the Likert scale (where 1 stands for "I fully disagree" and 5 stands for "I fully agree"). As the aim is to determine the correlation between dynamic capabilities, supporting sustainability and the building of competitive advantages in the three dimensions (economic, social and environmental) and performance, the questions in the survey are divided into four parts that follow the formulated hypotheses. In this way, the influence of the independent variables (the components in model of the dynamic capabilities of the second and first level and the functional competencies) on the dependent variable (competitive advantages and performance) can be
MARICHOVA A.

determined. The questions are formulated in an understandable way; the necessary explanations for certain terms have been added.

The influence of dynamic capabilities of second level on the competitive advantages in the survey was assessed by the following indicators/factors:

(a) Market dynamics (changes in demand, tastes, preferences).

(b) Market structure dynamics, competitive actions and reactions.

(c) Assessment of the legal framework, norms, standards, requirements and regulations.

(d) Method, frequency of analysis of the information gathered and evaluation of alternatives.

(e) Capacity to acquire, assimilate and create new knowledge, skills, new way of thinking.

(f) Active communication with direct and indirect stakeholders.

(g) Opportunities for the development of innovation and the company.

(h) Development of programs and plans for reconfiguration of existing functional competencies.

The influence of dynamic capabilities of first level on the competitive advantages in the survey was assessed by the following indicators/factors:

(a) Mechanism for integrating individual knowledge into a collective system.

(b) A new vision and development strategy.

(c) Coordination and building of loyalty of all stakeholders, which allows the firm to re-evaluate the resource and to use it in a new, more efficient way.

(d) Creating an integrated vertical management chain as a factor for development the circular economy.

(e) Allocation of tasks, resources and synchronization of business activities.

(f) Creating conditions for the implementation of strategic decisions and flexible adaptation.

Functional competencies are assessed on the basis of the following indicators/factors:

(a) Effective market segmentation, selection of target market.

(b) Effective marketing policy.

(c) Increasing the strength and value of the consumer brand, reputation and image of the firm.

(d) Reconfiguration, acquisition and integration of resources and capabilities. 
(e) Creating a new business model, based on the principles of sustainability.

(f) Development of innovation, counting patents.

(g) Management and organizational changes.

(h) Development of a system of incentives and motivation, conflict management and resolution.

The assessment of realization of competitive advantages and performance is made on some key indicators included in the GRI (12):

(a) Direct economic impacts (Customers, Suppliers, Employees, Public Sector).

(b) Environmental (Materials, Energy, Water, Biodiversity, Emissions and others).

(c) Labour practices (Employment, Labour/management relations, Training and others).

(d) Human rights (Strategy and management, Freedom of association and collective bargaining, Forced and compulsory labour and other).

(e) Society (Community, Bribery and corruption, Political contributions, Competition).
MARICHOVA A.

(f) Product Responsibility (Customer health and safety, Products and services, Advertising).

\section{RESULTS}

In the analysis of the results obtained from the online survey, the average values of the given answers are first calculated. On this basis, the Pearson coefficient (R) was calculated for the whole sample to establish the relationship between the dynamic capabilities (of second and first level), supporting sustainability and the change of functional competencies, as a factor for building competitive advantages in the three dimensions and performance. To add more explanatory power to the empirical results, the analysis also calculated and used a coefficient of determination ( \%) - $\mathrm{R}^{2}$, which gives a more accurate estimate and shows what percentage of changes in the independent variable leads to changes in the dependent (the remaining percentages up to 100 define the uncertainty coefficient) (Table 1).

Table 1. Correlation between the building of dynamic capabilities (of second and first level), the change of functional competencies and the realization of competitive advantages and performance

\begin{tabular}{|c|c|c|}
\hline & & $\begin{array}{l}\text { Competitive Advantages } \\
\text { (Economic, Environmental } \\
\text { and Social) and } \\
\text { Performance }\end{array}$ \\
\hline $\begin{array}{l}\text { Dynamic Capabilities of } \\
\text { Second Level, Supporting the } \\
\text { Sustainable Development of } \\
\text { the Firm }\end{array}$ & $\begin{array}{l}\text { Pearson Correlation }-\mathrm{R} \\
\text { Coefficient of Determination }(\%)-\mathrm{R}^{2} \\
\mathrm{~N}=123\end{array}$ & $\begin{array}{l}0.567 \\
32.14\end{array}$ \\
\hline $\begin{array}{l}\text { Dynamic Capabilities of First } \\
\text { Level, Supporting the } \\
\text { Sustainable Development of } \\
\text { the Firm }\end{array}$ & $\begin{array}{l}\text { Pearson Correlation }-\mathrm{R} \\
\text { Coefficient of Determination }(\%)-\mathrm{R}^{2} \\
\mathrm{~N}=123\end{array}$ & $\begin{array}{l}0.795 \\
63.20\end{array}$ \\
\hline $\begin{array}{l}\text { Change and Development of } \\
\text { Functional Competencies }\end{array}$ & $\begin{array}{l}\text { Pearson Correlation }-\mathrm{R} \\
\text { Coefficient of Determination }(\%)-\mathrm{R}^{2} \\
\mathrm{~N}=123\end{array}$ & $\begin{array}{l}0.683 \\
46.64\end{array}$ \\
\hline
\end{tabular}

Correlation is significant at the 0.01 level (1-tailed).

Source: Own calculations

The correlation between the realization of competitive advantages (economic, environmental and social) and performance as a function of building a system of dynamic capabilities, supporting sustainable development is also determined (Table 2). 
MARICHOVA A.

Table 2. Correlation between the realization of competitive advantages (economic, environmental and social) and performance as a function of building dynamic capabilities, supporting the sustainable development of the firm

\begin{tabular}{|l|l|l|}
\hline & & $\begin{array}{l}\text { Dynamic } \\
\text { Supporting the Sustainable } \\
\text { Development of the Firm }\end{array}$ \\
\hline $\begin{array}{l}\text { Competitive Advantages } \\
\text { (Economic, Environmental } \\
\text { and Social) and } \\
\text { Performance }\end{array}$ & $\begin{array}{l}\text { Pearson Correlation - R } \\
\text { Coefficient of Determination }(\%)-\mathrm{R}^{2} \\
\mathrm{~N}=123\end{array}$ & $\begin{array}{l}0.673 \\
45.29\end{array}$ \\
\hline
\end{tabular}

Correlation is significant at the 0.01 level (1-tailed).

Source: Own calculations

The obtained results allow to determine the influence of the individual indicators/factors on the construction of the dynamic capabilities (second and first order), supporting the sustainable development of the firm and the functional competencies on the building of competitive advantages, which are also evaluated according to the indicated indicators (Figure 2).

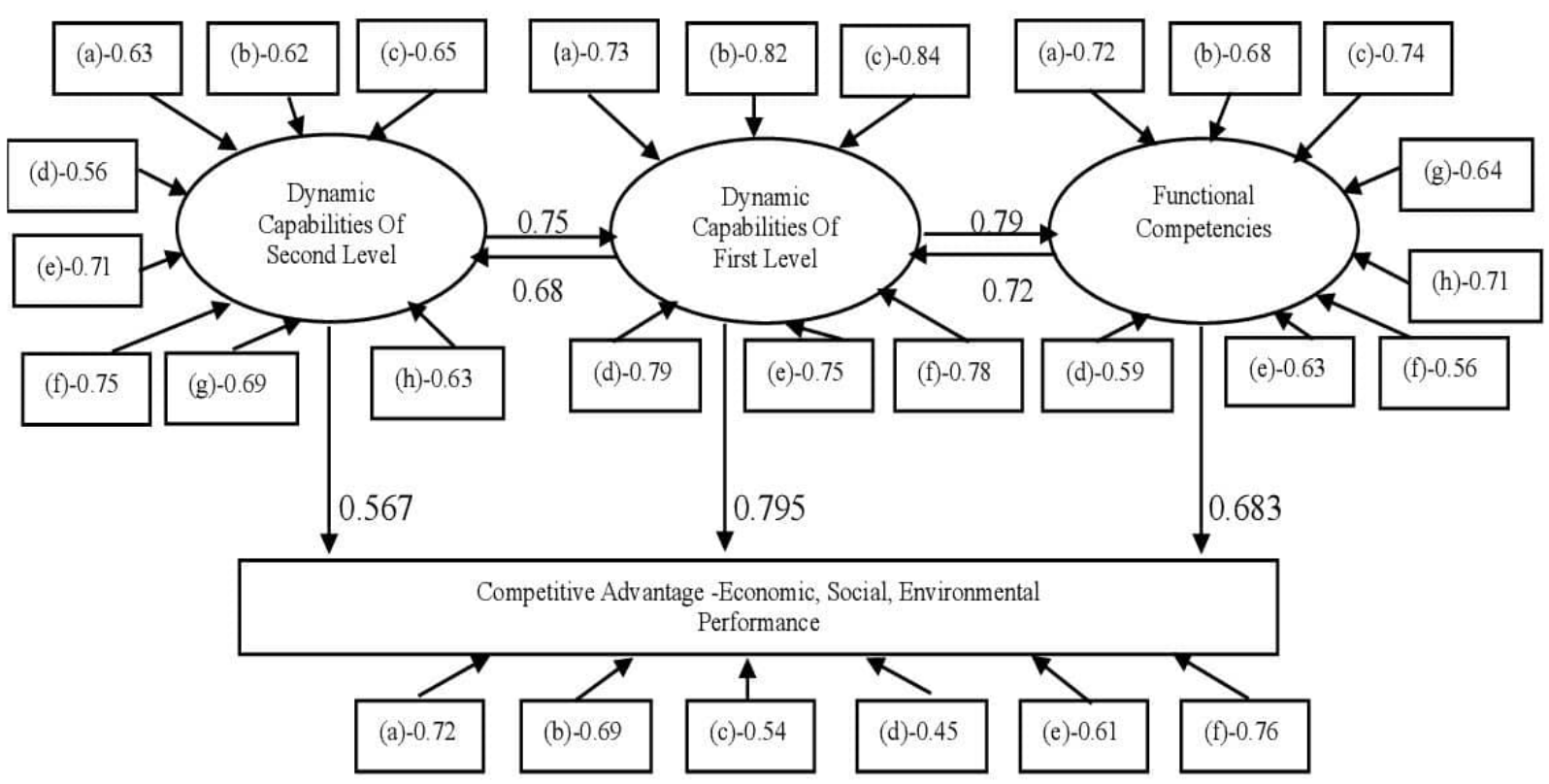

Figure 2. Influence of the individual indicators/factors of the dynamic capabilities (of second and first level) and the functional competencies on the building of competitive advantages

\section{CONCLUSION}

The results obtained in the empirical study prove the existence of a significant positive correlation between the dynamic capabilities (of second and first level), supporting the sustainable development of the firm, functional competencies and the building of competitive advantages in the three dimensions. The calculated Pearson correlation coefficient (Tables $\mathbf{1}$ and 2) is statistically significant, which proves the relationship between the studied variables and since it is significantly greater than zero, this by definition allows the rejection of the null hypothesis of their independence. The results that examine the relationship between the different dimensions of dynamic capabilities, functional competencies and competitive advantages are different and can be summarized as follows.

The surveyed managers understand the great importance of building dynamic capabilities of 
the second level as a factor for sustainable development and competitive advantages $(\mathrm{H} 1=0.567)$, but also the complex problems related to the legal framework, requirements and regulations, development of communication with direct and indirect stakeholders. Today the sustainable development of the company is based mainly on the development of intangible assets and above all the ability to create capacity to acquire, assimilate and create new knowledge, skills, a new way of thinking, which is a great challenge for any manager.

Respondents attach the greatest importance to the dynamic capabilities of first level, as a factor for sustainable development and competitive advantages $(\mathrm{H} 2=0.795)$. According to them, a radical change is needed in the strategic behavior, organization and management of the company's activities, which allow the creation of new configurations of resources and distinctive competencies. It is especially important to create an integrated vertical management chain that connects all participants not only physically through the product but also digitally, which allows expanding the business by adding new services, which increases the additional economic, social and environmental value offered to the customer, stakeholders and society at large.

Managers are adamant that a decentralized company structure, a system of incentives and motivation, the ability to coordinate the different goals of different groups and the firm as a whole, create identity, culture, loyalty and reputation and ultimately a new business model can ensure successful adaptation and coordination of internal resources and competencies to external changes, which is a factor for competitive advantage $(\mathrm{H} 3=0.683)$.

The study demonstrates the system of dynamic opportunities as a particularly important factor for building competitive advantages - economic (high user rating), social (labor practices, human right, product responsibility) and environmental (reducing the negative impact on the environment) and performance, measured in financial indicators $(\mathrm{H} 4=0.673)$.
MARICHOVA A.

The main limitation of the present study is the subjective nature of the responses on the one hand. On the other hand, the developed model of dynamic capabilities, supporting the sustainable development of the company, does not answer all questions because it includes common characteristics (or known good practices). These general characteristics should be applied specifically in different companies, because they have different organizational characteristics, abilities and skills and differ in their history, experience, knowledge, routine, specialization and more. In each firm, managers should develop specific solutions and apply specific methods, approaches, analytical procedures and routine actions in order to build the system of dynamic capabilities and its integration into the overall organizational structure to ensure the sustainability. Especially important for the company's success is the application of a unified, complex approach in the process of creating sustainable practices that skillfully combine the development of internal and external factors/resources. The dynamic capability model developed in this article makes it easier for managers to solve problems and improve activities that ensure sustainable development and competitive advantages of the firm.

\section{REFERENCE}

1. WCED, Our Common Future. The World Commission on Environment and Development. NY, Oxford University Press, 1987.

2. Goldsmith, S. and Samson, D., Sustainable Development and Business Success. A Report of the Australian Business Foundation and the Foundation for Sustainable Economic Development at the University of Melbourne, 2005.

3. Eisenhardt, K. and Martin, J., Dynamic capabilities: What are they? Strategic Management Journal, 21:1105-1121, 2000.

4. Teece, D., Pisano G.and Shuen A., Dynamic capabilities and strategy management. Strategic management Journal., 18:509-533, 1997.

5. Eisenhardt, K. and Martin, J., Dynamic capabilities: What are they? Strategic Management Journal, 21:1105-1121, 2000. 
6. Zollo, M. and Winter, S. Deliberate learning and the evolution of dynamic capabilities. Organization Science. 13:339-351, 2002.

7. Helfat, C., Finkelstein, S., Mitchell, W., Peteraf, M., Singh, H., Teece, D., and Winter, S., Dynamic capabilities: Understanding strategic change in organizations. London: Blackwell, 2007.

8. Wang, C. and Ahmed, P., Dynamic capabilities: A review and research agenda. International Journal of Management Reviews, 9:31-51, 2007.

9. Protogerou, A., Caloghirou Y. and Liokas,S., Dynamic Capabilities and their Indirect Impact on Firm Performance. www.druid.dk., 2004.
MARICHOVA A.

10. Ivanova, V., Circular Economy: Barriers and Levers Promoting Transformation (Case Study Analysis), Management and Business Research Quarterly, 16:14-28, https://doi.org/10.32038/mbrq.2020.16.02,2020

11.Wu, Q., He, Q. and Duan Y., Explicating dynamic capabilities for corporate sustainability. EuroMed Journal of Business, 8: 55-272, DOI 10.1108/EMJB-05-20130025, 2013.

12.Global Reporting Initiative - GRI, Sustainability Reporting Guidelines. Boston, MA 02116 USA, www. globalreporting.org, 2002. 